\title{
Correction to: Platelet-Derived Growth Factor-BB Restores HIV Tat-Mediated Impairment of Neurogenesis: Role of GSK-3 $\beta / \beta$-Catenin
}

Jie Chao ${ }^{1} \cdot$ Lu Yang $^{1} \cdot$ Honghong Yao ${ }^{1} \cdot$ Shilpa Buch ${ }^{1}$

Published online: 28 October 2020

(C) Springer Science+Business Media, LLC, part of Springer Nature 2021

Correction to: J Neuroimmune Pharmacol (2014) 9:259-268 https://doi.org/10.1007/s11481-013-9509-x

We have now noticed that the wrong image of NPCs treated with PDGF-BB alone was inadvertently included in Fig. 1B. Also, the western blot images of GSK-3 $\beta$ was inadvertently included in Fig. 4C. The figures are corrected as shown below. The authors declare that these amendments do not change the result or conclusion of the paper, and apologize for this oversight.
The online version of the original article can be found at https://doi.org/ 10.1007/s11481-013-9509-x

Honghong Yao

hyao@unmc.edu

Shilpa Buch

sbuch@unmc.edu

1 Department of Pharmacology and Experimental Neuroscience, 985880 Nebraska Medical Center (DRC 8011), University of Nebraska Medical Center, Omaha, NE 68198-5880, USA

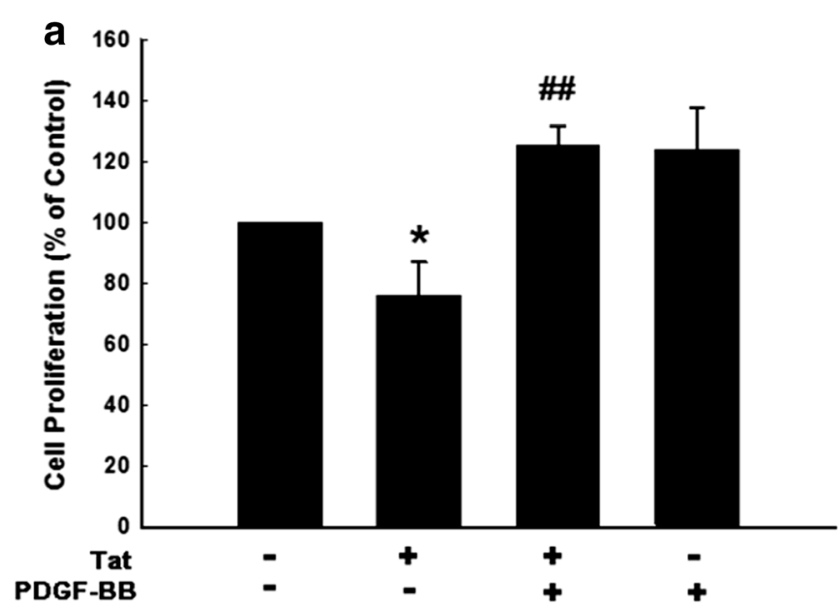

b
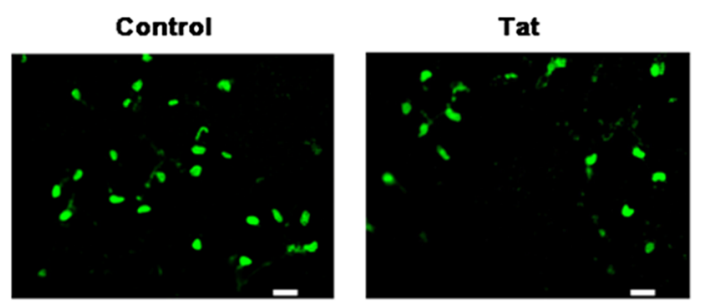

PDGF-BB+Tat

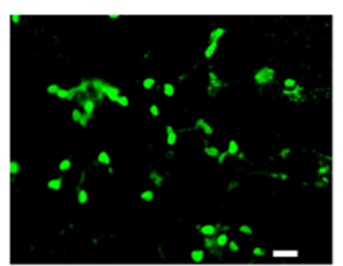

PDGF-BB

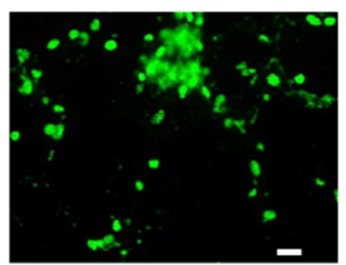

Fig. 1 
a
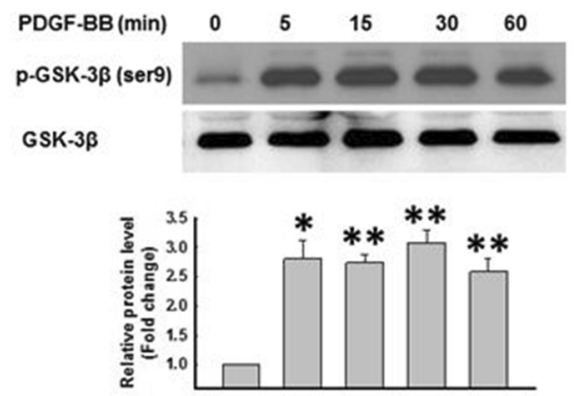

C

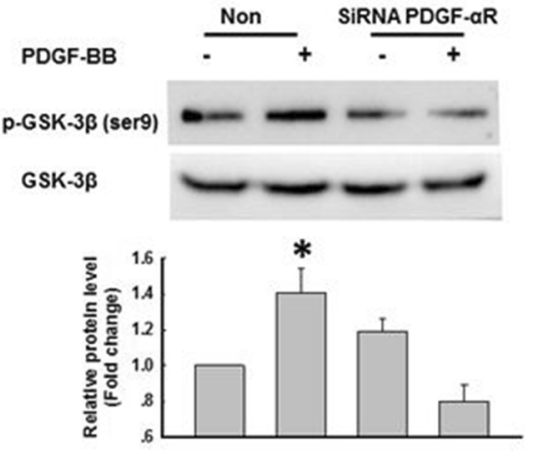

e

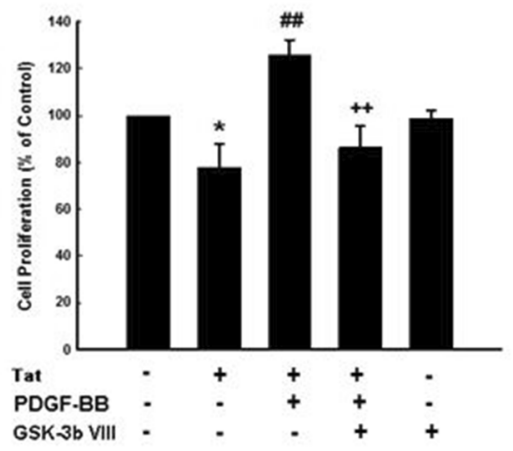

Fig. 4

Publisher's Note Springer Nature remains neutral with regard to jurisdictional claims in published maps and institutional affiliations. b
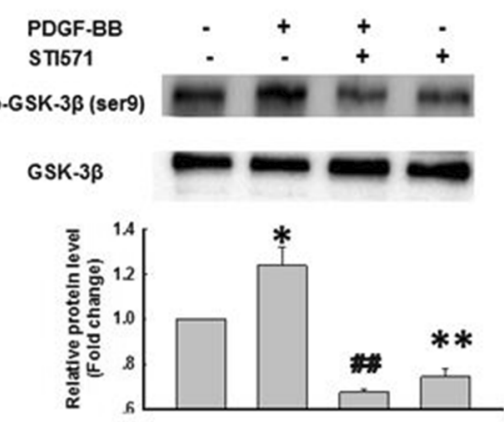

d

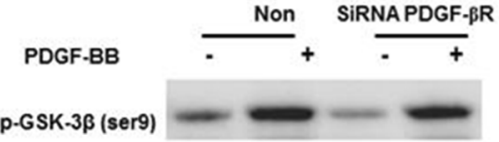

GSK-3 $\beta$

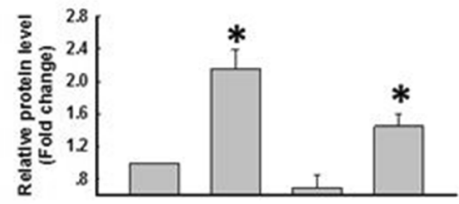

f

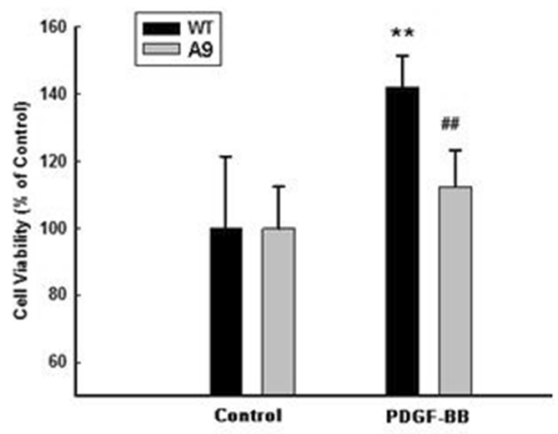

